\title{
Üniversite Öğrencilerinin Mutluluk, Yalnızlık ve Sabır Düzeyleri Arasındaki İlişkinin İncelenmesi
}

\author{
DOI: 10.26466/opus.575329
}

\section{Zeliha Traș - Kemal Öztemel ${ }^{* *}$ - Merve Koçak***}

* Prof. Dr, Necmettin Erbakan Üni.,Ahmet Keleşoğlu Eğitim Fakültesi, Meram / Konya / Türkiye E-Posta: zztras@gmail.com ORCID: 0000-0003-2670-0868

** Doç. Dr., Gazi Üniversitesi, Gazi Eğitim Fakültesi, Yenimahalle / Ankara / Türkiye E-Posta: koztemel@gmail.com ORCID: 0000-0002-8068-3897

*** Yüksek Lisans Öğrencisi, Necmettin Erbakan Üni., Eğitim Bilimleri Ens., Meram/ Konya/ Türkiye E-Posta: 1kocakmerve@gmail.com ORCID: $\underline{0000-0003-4528-2761}$

\section{$\ddot{O} \mathbf{z}$}

Bu çalışmada üniversite öğrencilerinin mutluluk, yalnızlık ve sabır düzeyleri arasındaki ilişkinin incelenmesi amaçlanmıştır. Araştırma ilişkisel tarama modelindedir. Araştırmanın çalışma grubunu İç Anadolu'da bir devlet üniversitesinde, çeşitli bölümlerde eğitim gören öğrenciler oluşturmaktadır. Araştırma 227'si (\%75.7) kadın, 73'ü (\%24.3) erkek olmak üzere 301 öğrenciden oluşmaktadır. Araştırma verilerinin toplanmasında "Oxford Mutluluk Ölçeği", "Sabır Ölçeği" ve "Sosyal Duygusal Yalnızlık Ölçeği" kullanılmıştır. Verilerin analizinde Pearson Korelasyon Katsayısı tekniği ile çoklu regresyon analizi tekniği kullanılmıştır. Korelasyon analizi sonucuna göre; üniversite öğrencilerinin; mutluluk ve yalnızlık ölçeğinden aldıkları puanlar arasında düşük düzeyde anlamlı negatif bir ilişki, mutluluk ve sabır arasında orta düzeyde anlamlı pozitif bir ilişki, yalnızlı ve sabır arasında ise düşük düzeyde anlaml negatif ilişki olduğu saptanmıştır. Yapılan regresyon analizi sonucunda ise sabır, yalnızlık değişkenleriyle birlikte üniversite öğrencilerinin mutluluk puanların anlamlı şekilde yordamaktadır. Yalnızlık ve sabır değişkenleri mutluluk puanlarının toplam varyansın \%33'ünü yordamaktadır. Araştırma sonucunda elde edilen bulgular alan yazın kapsamında ele alınmış ve literatür ışı̆̆ında tartışılmıştır.

Anahtar Kelimeler: Mutluluk, yalnızlık, sabır, üniversite öğrencileri 


\title{
An Examination of the Relationship between Happiness, Loneliness and Patience Levels of Univesity Students
}

\begin{abstract}
The aim of this study is to analyze the relationship between happiness, loneliness, and patience levels of university students. The research is in relational scanning model. The research has been applied to 301 university students. In various departments of University participants of in this study that are 227 (\%75.7) female and 73 (\%24.3) male. Oxford Happiness Scale, Patience Scale, Social Emotional Loneliness Scale are used to collect data Pearson Correlation Coefficient technique and multiple regression analysis tecnique are used in the analysis data. As a result of correlation analsis; there is a significant and low negative correlation between the scores of happiness and loneliness scale ( $r$ : -.292, $p<.01)$, there is a significant and medium positive correlation between the scores of happiness and patience $(r: .535, p<.01)$, there is a significant and low negative correlation between the scores of loneliness and patience $(r:-.131, p<.01)$. As a result of the regression analysis patience predicts happiness scores of university students loneliness variables significantly $(R=.580, R 2=.336, p<.001)$. The findings are discussed in the light of the literature. According to the result of this research; it is thought that it can contribute positively to determination of the variables that cause the individuals to be unhappy and to increase to individuals' happiness.
\end{abstract}

Keywords: Happiness, Patience, Loneliness, University students 


\section{Giriş}

Geçmişten günümüze kadar psikolojiyle ilgili pek çok konu araştırılmaktadır. Bu çalışmalar başta ruhsal bozukluklara, olumsuzluklara odaklansa da günümüzde ruhsal sağlığı yerinde olan bireylerle ilgili de çalışmalar önem kazanmaya başlamıştır. Bu çalışmalar ise psikolojide olumluya odaklanılması gerektiğini savunmaktadır. İşte bu anlayış pozitif psikoloji olarak adlandırılmaktadır. Pozitif Psikoloji geçmişle ilgili hoşnutluk, memnun olma, iyi oluş; gelecekle ilgili iyimserlik ve ümit; şimdiki zamanla ilgili mutluluk şeklinde değerlendirilir (Seligman ve Csikszentmihalyi, 2000). Pozitif psikolojinin önemli kavramlarından biri mutluluktur. İnsanlar geçmişten günümüze mutlu olmayı istemiş ve bunun yollarını aramışlardır. Bu nedenle mutlulukla ilgili pek çok araştırma yapılmaktadır. Mutluluk bir duygu ve bu duygu anında hissedilen hoşnutluk durumudur. Mutluluk yerine kullanılabilecek bazı kavramlar arasında öznel iyi oluş, yaşam memnuniyeti sayılabilmektedir. İnsanın mutluluk seviyesi yaşamını ne kadar olumlu değerlendirebildiğiyle alakalıdır (Bülbül ve Giray, 2011). Kişinin hayatı boyunca üretkenliğinin ve hareketliliğinin çoğalması, fikirlerinin duygularının olgunlaşması mutluluğu tanımlar. Bu işlevlerin zayıflaması ise mutsuzluğa sebep olur. Stres, baş ağrısı, bıkkınlık mutsuzluğun bedensel belirtileri olarak görülebilir. Mutluluk hali bireyin ruhsal açıdan daha pozitif olmasını ve kendisini de daha iyi hissetmesini sağlar (Fromm, 1994). İnsanların yaşamda karşılaştığı problemlere çözüm bulma azmi de mutluluğu sağlar. İlk başta problemle karşılaşılır ve bu problem insanda stres ve huzursuz bir hal oluşturur. Bu huzursuz durumun yok edilmesi istenir ve problemle mücadele edilir. Gayret sonucunda sorun çözülmüşse stres ve huzursuzluğun yerini huzura, rahatlamaya bırakır. Bu durum mutlulukla ifade edilebilir (Döş, 2013; İlhan,2009). Mutluluk tesadüfi ya da şans eseri olan bir şey değildir. Paranın sahip olabileceği bir şey de değildir. Dış olaylara değil de onların nasıl algılanıldığına bağlı bir kavramdır. Esasında mutluluk kavramı, her kişinin özel olarak hazırlanması, geliştirmesi gereken bir durumdur. İçsel yaşantıyı kontrol etmeyi öğrenen insanlar, yaşamlarının niteliğini belirleyebileceklerdir ve herhangi bir kişi mutlu olmaya ancak bu kadar yaklaşabilecektir (Csikszentmihalyi, 2005). Pozitif psikoloji ile ilgili araştırmalar incelendiğinde üzerinde durulan kavramlardan birinin de "öznel iyi oluş" olduğu görülmektedir. Öznel 
iyi oluş (mutluluk); negatif duyguların az, pozitif duyguların ise daha fazla yaşanması ve kişinin fazlaca yaşam doyumu alması olarak açıklanmaktadır (Diener, 1984; Myers ve Diener 1995). Öznel iyi oluş; kısa süreli duygu durumlarına değil daha uzun süreli duygu durumlarına göre şekillenir. Gün içerisinde inip çıkan duygu durumlarından ziyade daha genel ruhsal durumla ilgilenirler. Kısa süreli mutluluk hali, uzun süreli mutluluk (öznel iyi oluş) hakkında doğru bilgi vermeyebilir (Diener, Suh ve Oishi, 1997). Mutlulukla ilişkisinin incelendiği değişkenlerden biri yalnızlıktır. Arkadaş çevresinin fazla olmasıyla birlikte yalnızlığı hissetmeme kişinin mutlu olmasında mühim bir faktördür (Cheng ve Furnham, 2002). Araştırmacılar evli, sosyal iletişimleri güçlü, arkadaş çevresi fazla kişilerin yani yalnız olmayan kişilerin daha mutlu olduğunu söylemişlerdir (Lyubomirsky, Sheldon ve Schkade, 2005). Sosyal ilişkilerde kişinin kendisini dışlanmış, kabul edilmemiş, yanlış anlaşılmış ve duygusal açıdan insanlarla ilişki kuramamış olmasından dolayı ortaya çıkan duruma yalnızlık denir (Ünlü, 2015). Yalnızlık, kişinin bireysel olarak kendini yetersiz hissettiğinde ortaya çıkan ve sahip olduğu kişilerarası ilişkileriyle arzuladığı kişilerarası ilişkileri arasında farkın olmasıdır (De Jong-Gierveld, 1998). Weiss (1973) yalnızlığı, bireyin sosyal ilişkilerindeki eksikliğe ya da var olan sosyal ilişkilerindeki doğallığın, yakınlığın, duygusallığın bulunmamasına yönelik gösterilen tepki olarak açıklamıştır.

Yalnızlık; bireyin diğer insanlarla hiç yakın ilişkisinin olmadığını hissetmesi olarak ifade edilirken (Rogers,1994), bireyin hisleri, duyguları başkaları tarafından kabul edilmediğinde ya da farklı şekilde anlaşıldığında sosyal aktivitelerde programlarda yanında birisinin olmadı̆̆ zaman ortaya çıkan kaygı verici bir durum olarak da tanımlanmaktadır (Rook,1984). Birey toplumun beklentilerini giderecek etkileşimleri sağlayamadığında bu durum yalnızlıkla sonuçlanır. Weiss (1973), kişinin yalnız olmasında çevresel faktörlerin daha baskın olduğunu savunur. Yalnızlık kişinin başkalarıyla hiçbir gerçek ilişkisinin olmadığını anladığı zaman ortaya çıkmaktadır. Kişinin yalnızlıktan kurtulmasının ise sevilmeyeceği, değerli olmadığı, başkaları tarafından reddedileceğine olan düşüncesini değiştirmesiyle olabileceğini söyler (Rogers, 1994). Tek başına olmakla yalnızlık tanımları bazen birbirine karıştırılmaktadır. Tek başına olan birey yalnız olmayı kendisi seçmiştir ve tek başına olan birey diğer bireylerden rahatlıkla bağımsızlaşabilir (Larson, 1990). Weiss (1973) yalnızlığı ikiye 
ayırmıştır. Duygusal yalnızlık ve sosyal yalnızlık. Weiss'e göre bireyin ilişkileri samimi değil de yüzeysel olursa yalnızlık duygusunu daha fazla yaşar. Kişi duygusal yalnızlığı çocukluk çağında terk edilme duygusuyla fazlaca yaşar. Ayrıca duygusal yalnızlık, bağlanmayla ilgilidir. Duygusal bir bağ kurduğu sevdiği kişiden ayrılan, eşinden boşanan, sevgilisinden ayrılan kişilerde rastlanır. Sosyal yalnızlık ise kişinin çevresinde ihtiyaç duyduğu bir arkadaşlığın olmaması şeklinde tanımlanır. Sosyal yalnızlık hisseden bireyler kendilerini toplumdan ayrışmış olarak görür. Kısaca; sosyal yalnızlık, kişinin etrafında, arkadaşlık ilişkisi kurabileceği hiç kimsenin olmamasıyken; duygusal yalnızlık, kişinin çevresindeki arkadaş, eş, sevgili gibi yakınındaki insanlarla samimi, içten ilişkiler kuramaması olarak tanımlanır. Psiko-sosyal gelişim kuramına göre Erikson, "temel güvene karşı güvensizlik" aşamasında temellenip ve şekillenen yalnızlık, genç yetişkinlikte "yakınlığa karşı yalıtılmışlık" evresinde belirgin şekilde ortaya çıkmaktadır. Bu dönemde genç yetişkin; arkadaşlarıyla yakın ilişkide olma, karşı cinsle duygusal ilişki halinde olma, evlenme ihtiyacını hisseder. Eğer bu yakınlığı sağlarsa bu evreyi başarıyla atlatır fakat sağlayamazsa bu evreyi krizle atlatır ve yalnızlık duygusunu yaşar (Burger, 2006). Bağlanma kuramı, yeni doğan bebekte mevcut olan ve yetişkinlikten yaşl1lığa kadar da devam eden insan yaşamının temel parçası olarak belli bireylere yakın duygusal bağlar kurma ile ilgilidir. Bebeklikte ve çocuklukta bu bağlar yakın ilişkide olduğu rahatlığı, koruması ve desteğine güvenilen ebeveynleridir ya da onun yerine geçen yakınlarıdır. Sağlıklı ergenlik ve yetişkinlik yaşamlarında bu bağlar devam eder. Eğer bu güvenli bağ oluşmazsa kaygılı dirençli bağlanma, kaygılı kaçınmalı bağlanma gibi bağlanma stilleri ortaya çıkar. Kaygılı kaçınmalı bağlanmada birey yaşamını diğerlerinin sevgisi ve desteği olmadan, yalnız bir şekilde yaşamayı tercih eder (Bowlby, 2014).

Mutluluğa etkisinin düşünüldüğü kavramlardan birisi de sabırdır. Sabır, düş kırıklığı acı, stres, dert karşısında bireyin sakince bekleme halidir (Schnitker, 2012). Sabır her çeşit stres, güçlük, yitim karşısında razı olarak sonuçlara katlanma, dayanma, mücadele etmeyle birlikte duyuşsal, zihinsel ve davranışsal durumlarla yaşanan bir süreçtir. Bireyin hayatının sonuna kadar karşılaştığı zorluklarda güç veren sabır onu başarıya götürür ve ardından mutlu olmasına aracilık eder (Doğan ve Gülmez, 2014). Sabır insanın hayatında uzun vadeli planlar yapabilmesine yardımcı olmaktadır 
(Aahababaei, 2015). Sabır iki başlık altında incelenebilir: Durumluluk sabır ve sürekli sabır. Durumluluk sabırda birey sabrı uzun sürede kazanmamış olsa da koşullar sıkıntıya girdiğinde zorunluluktan sergiler. Ancak Aristotales'e göre insan adil davrandıkça adil, ölçülü oldukça ölçülü, mertçe davrandıkça mert olmaktadır (Maclntyre, 2001). Dolayısıyla birey sabırlı ola ola "sürekli sabır" tutumunu geliştirebilir. Durumluluk sabır, sabır kavramının ilk aşaması olarak kabul edilebilir, sürekli sabır ise bir tutumdur (Doğan ve Gülmez, 2014). Schnitker (2012), sabır kavramını 3 ayrı kategoride toplamıştır:

1. Gündelik hayatta sabır: Kısa süreli sabırdır. Gündelik hayatta sık karşılaşılan bekleme durumlarıdır. Trafikte bekleme, otobüs-uçak kalkış vaktinin gelmesini bekleme, sipariş edilen yemeğin gelmesini bekleme gibi.

2. Yaşam zorluklarında sabır: İnsanların zorlu yaşam olaylarıyla karşılaştıklarında sergiledikleri uzun süreli sabırdır. Ekonomik problemler, uzun süren hastalıklar, işsizlik gibi.

3. Kişiler arası sabır: İnsanın kişiler arası ilişkilerinde gösterdiği tahammüldür. İş yerindeki zorlu patron, ebeveynler, okuldaki yaramaz öğrenciler gibi.

Sabır ve tahammül aynı kavramlar gibi gözükse de aralarında fark vardır. Sabırda zorluklar, problemler karşısında gönüllü bir dayanma, direniş, mücadele etme, karşılaşılan acıyı sıkıntıyı sükunetle sakinlikle karşılama ve bu sıkıntılara çözüm yolu arama vardır. Tahammülde ise sıkıntılara karşı zoraki katlanma, mecburi katlanış vardır (Özdoğan, 2006). Sabır ile haz erteleme de aynı şey değildir. Haz ertelemede gelecekteki daha büyük bir ödül için şu anki ödülü erteleme davranışı vardır içinde sabrı da barındırır fakat tamamen sabır kavramının, haz ertelemeye indirgenmesi doğru değildir. Haz ertelemede beklemenin sonucunda bireyi memnun edecek sonuçlar vardır ama sabırda her zaman beklemenin sonucunda bireyi hoşnut edecek sonuçlar olmayabilir (Schnitker, 2012). Sabır kavramı karşısında yer alan acelecilik tutumunun olumsuz psikolojik özelliklerden sayılması ve hız faktörünün son dönem insanlarını sarmasından dolayı sabır kavramının önemi artmış gözükmektedir. Fakat psikoloji literatüründe sabırla ilgili daha az araştırmaya rastlanılmıştır (Doğan ve Gülmez, 2014). 
$\mathrm{Bu}$ çalışmanın amacı üniversite öğrencilerinin mutluluk, yalnızlık ve sabır düzeyleri arasındaki ilişkisinin incelenmesidir. Bu amaç doğrultusunda araştırmada şu temel sorulara yanıt aranmıştır:

1. Üniversite öğrencilerinin yalnızlık, sabır ve mutlulukları arasında anlamlı bir ilişki var mıdır?

2. Üniversite öğrencilerinin yalnızlık ve sabır düzeyleri mutluluklarını anlamlı düzeyde yordamakta mıdır?

\section{Yöntem}

\section{Araştırma Modeli}

Yapılan araştırma, ilişkisel tarama modeline göre gerçekleştirilmiştir. Tarama modeli, geçmişte olan ya da devam eden durumu olduğu gibi tespit etmeyi amaçlayan modeldir. Araştırma konusu olan birey, hadise, nesne kendi şartları içinde ve olduğu gibi açıklanmaya çalışılır ( Karasar, 2018).

\section{Çalışma Grubu}

Bu çalışmanın katılımcıları, İç Anadolu'da bir devlet üniversitesinde eğitim ve öğretim gören 301 öğrenciden oluşmaktadır. Üniversite öğrencileri, çalışma evrenindeki elemanların eşit seçilme şansına sahip olduğu basit tesadüfi (yansız örnekleme) örnekleme yöntemi ile seçilmiştir (Karasar, 2018). Katılımciların 227'si (\%75,7) kadın, 73'ü (\%24.3) erkektir. 1. sinıfta 119 kişi (\%39.5), 2. sinıfta 132 kişi (\%43.9) ve 3.sınıfta 50 kişi (\%16.6) bulunmaktadır. Katılımcıların yaşları 17 ile 37 arasındadır ( $\mathrm{ss}=2.20)$.

\section{Veri Toplama Araçları}

Oxford Mutluluk Ölçeği: OMÖ, Hills ve Argyle tarafından geliştirilmiştir. 6'lı likert tipi ve 29 maddeden oluşan bir ölçme aracıdır. Hills ve Argyle, ölçeğin cronbach alpha değerini 0.91 olarak rapor etmişlerdir. Oxford Mutluluk Ölçeği (OMÖ) Türkçe formu, tek faktörlü bir yapıdadır. Mutluluğu ölçen diğer ölçme araçları ve OMÖ Türkçe formu arasında yüksek düzeyde ilişki vardır. OMÖ Türkçe formu, üniversite öğrencilerinde mutluluğu belirlemede geçerli ve güvenilir bir ölçme aracı olarak kullanılabilir 
(Doğan ve Sapmaz, 2012). OMÖ'de yüksek puanlar, mutluluk düzeyinin yüksek olduğu anlamına gelmektedir. Bu araştırma için Cronbach Alpha değeri $0.88^{\prime}$ dir.

Sabır Ölçeği: Schnitker ve Emmons (2007) tarafından geliştirilen ölçek Eliüşük, Arslan (2016) tarafından uyarlama çalışması yapılmıştır. Sabır ölçeği, bireylerin sabır kavramının önemi hakkındaki inançlarını ve sabır davranışının sabrın öz-değerlendirilmesi için kullanılmaktadır. Ölçekte uzun süreli, kısa süreli ve kişilerarası olmak üzere üç alt boyut bulunmaktadır. Toplamda 11 madde bulunmaktadır ve yedili likert tipi bir ölçektir. Ölçeğin iç tutarlılık katsayısı .80 'dir. Sabır ölçeğinin faktör yapılarını belirlemek amacıyla doğrulayıcı faktör analizi yapılmıştır. Doğrulayıcı faktör analizi sonuçlarına göre ölçeğin üç boyutlu olduğu doğrulanmıştır. Sabır ölçeğinin madde toplam korelasyonunda ölçeğin maddeleri arasında .40'ın üzerinde ilişki bulunmuştur. Sabır ölçeğinin her madde için madde faktör değerleri .50 ile .84 arasında değişmektedir. Ölçeğin Cronbach Alpha iç tutarlılık katsayısı .82 ve test tekrar test korelasyon değeri .81 olarak hesaplanmıştır. Bu araştırma için Cronbach Alpha değeri 0.83'tür.

Sosyal Duygusal Yalnızlık Ölçeği: Ölçek DiTommaso, Brannen ve Best (2004) tarafından geliştirilmiştir. Daha sonra Türkçeye uyarlama işlemi Çeçen (2007) tarafından yapılmıştır. Ölçek likert tipi olup kendini bildirim türünde bir ölçektir. 15 maddeden oluşmaktadır, "bana tamamıla uygun değil" seçeneğine (1) puan, "bana tamamıyla uygun" seçeneğine (7) puan verilmektedir. Ölçekten alınabilecek max puan 105, min puan $15^{\prime}$ tir. Ölçek aile ile ilişkiler, romantik ilişkiler ve sosyal ilişkiler olmak üzere üç boyuttan oluşmaktadır. Ölçeğin sosyal boyutunu sosyal ilişkiler oluştururken duygusal boyutunu ise romantik ilişkiler ve aile ile ilişkiler oluşturmaktadır. Ölçeğe ilişkin Cronbach alpha değerleri ise sosyal yalnızlık alt boyutu için .71, duygusal yalnızlık için .68, ölçeğin bütünü için ise .68 olarak bulunmuştur. Sosyal ve duygusal yalnızlık ölçeğinin geçerlik ve güvenirlik çalışmaları üniversite öğrencileri üzerinde yürütüldüğü için ölçeğin üç faktörden oluşan yapısının ergenlerde uyum sağlayıp sağlamadığı doğrulayıcı faktör analiziyle test edilmiştir. Doğrulayıcı faktör analizinde sosyal yalnızlığın sosyal ilişkilerdeki yalnızlık, duygusal yalnızlığın ise aile ve romantik ilişkilerdeki yalnızlık alt boyutları ile ölçüldüğü üç faktörlü yapı 
test edilmiş ve bu yapının ergenlerden oluşan örnekleme uyum sağlamadığı görülmüştür. Duygusal yalnızlığın aile ilişkilerindeki yalnızlık, sosyal yalnızlığın ise sosyal ilişkilerdeki yalnızlık alt boyutlarıyla ölçüldüğü iki faktörlü ölçme modelinin iyi uyum $(\chi 2 / \mathrm{sd}=4.05$, RMSEA=.074, CFI=.95, $\mathrm{GFI}=.96, \mathrm{IFI}=.95, \mathrm{AGFI}=.93$, SRMR=.068) verdiği görülmüş ve daha sonraki analizlerde bu ölçüm modeli temel alınmıştır. Bu araştırma için Cronbach Alpha değeri 0.74 'tür.

Kişisel Bilgi Formu: Katılımcıların cinsiyet, yaş, sınıf düzeyi, romantik ilişki durumları vb bilgiler elde edilmiştir.

\section{Veri Toplama Süreci}

Gönüllü olan öğrencilere sınıflarında “Oxford Mutluluk Ölçeği, Sabır Ölçeği, Sosyal Duygusal Yalnızlık Ölçeği ve Kişisel Bilgi Formu" uygulanmıştır. Uygulama ortalama 15 dakika sürmüştür. Veri toplama aşamasında, gizlilik, bilgilendirilmiş onay gibi etik konular dikkate alınmıştır.

\section{Verilerin Analizi}

Verilerin analizi için bağımlı değişkenle (mutluluk) ilişkili iki ya da daha fazla bağımsız değişkene (sabır ve yalnızlık) bağlı olarak bağımlı değişkenin tahmin edilmesine yönelik analiz olan çoklu doğrusal regresyon kullanılmıştır (Büyüköztürk, 2018). Ölçeklerden elde edilen puanlar arasındaki ilişki, Pearson Korelasyon katsayısı kullanılarak hesaplanmıştır. Araştırmada veriler SPSS 20.0 paket programı kullanılarak analiz edilmiştir.

\section{Bulgular}

Tablo 1. Bă̆ımlı Değişken ve Bă̆ımsız Değişkenler için Korelasyon Dĕ̆erleri

\begin{tabular}{lccc}
\hline & $\mathbf{1}$ & $\mathbf{2}$ & $\mathbf{3}$ \\
\hline Mutluluk & - & $-.292^{* *}$ & $.535^{* *}$ \\
Yalnızl1k & $-.292^{* *}$ & - & $-.131^{*}$ \\
Sabir & $.535^{* *}$ & $-.131^{*}$ & - \\
\hline
\end{tabular}

**. $P<.01 \quad * . P<.05$ 
Bağımlı değişken olan mutluluk ve bağımsız değişkenler (yalnızlık, sabır) arasındaki korelasyon değerleri Tablo 1'de verilmiştir. Değişkenler arasında anlamlı ilişkiler bulunmaktadır. Mutluluk puanları yüksek olan öğrencilerin sabır puanları yüksek $(\mathrm{r}=.535, \mathrm{p}<.01)$, yalnızlık puanları düşüktür $(\mathrm{r}=-.292, \mathrm{p}<.01)$. Yalnızlık puanları yüksek olan öğrencilerin ise sabır puanları düşüktür $(\mathrm{r}=-.131, \mathrm{p}<.01)$.

Tablo 2. Mutluluğun Yordanmasına İlişkin Çoklu Regresyon Analizi Sonucu

\begin{tabular}{lcccc}
\hline Değişkenler & B & SE & $\beta$ & T \\
\hline Sabır & 1.368 & .129 & .506 & 10.620 \\
Yalnızlık & -.336 & .071 & -.226 & -4.740 \\
\hline
\end{tabular}

$\mathrm{R}=.580, \mathrm{R}^{2}=.336, \mathrm{p}<.001 \quad{ }^{* *} \mathrm{p}<.01,{ }^{* * *} \mathrm{p}<.001$

Tablo 2 incelendiğinde sabır, yalnızlık değişkenleriyle birlikte üniversite öğrencilerinin mutluluk puanları yüksek düzeyde ve anlamlı bir ilişki vermektedir ( $\left.\mathrm{R}=.580, R^{2}=.336, \mathrm{p}<.001\right)$. Yordayıcı değişkenlerle birlikte, mutluluktaki toplam varyansın \%33'ünü yordamaktadır. Standardize edilmiş regresyon katsayısına $(\beta)$ göre bağımsız değişkenlerin mutluluk üzerindeki göreli önem sırası; sabır $(\beta=.506, \mathrm{t}=10.620, \mathrm{p}<.001)$ ve yalnızlık$\operatorname{tr}(\beta=-.226, \mathrm{t}=-4.740, \mathrm{p}<.001)$.

\section{Tartışma}

Bu çalışmanın amacı üniversite öğrencilerinin mutluluk, yalnızlık ve sabır düzeyleri arasındaki ilişkisinin incelenmesidir. Bulgulara göre, sabır, yalnızlık değişkenleriyle birlikte üniversite öğrencilerinin mutluluk puanları yüksek düzeyde ve anlamlı bir ilişki bulunmuştur. Bağımsız değişkenlerle birlikte, mutluluktaki toplam varyansın \%33'ünü yordamaktadır. Bağımlı değişken olan mutluluk ile bağımsız değişkenler (yalnızlık, sabır) arasında anlamlı ilişkiler bulunmaktadır. Mutluluk puanları yüksek olan öğrencilerin sabır puanları yüksekken, yalnızlık puanları düşüktür. Yalnızlık puanları yüksek olan öğrencilerin ise sabır puanları düşüktür.

Mutluluk ile yalnızlık ölçeği puanları arasında anlamlı düşük düzeyde negatif ilişki bulunmuştur. Başka ifadeyle üniversite öğrencilerinde mutluluk arttıkça yalnızlığın azaldığı görülmüştür. Bu bulguyu destekler nitelikte çalışmalar mevcuttur. Csikszentmihalyi, "Mutluluk Bilimi-Akışs" adlı 
kitapta insanlar için en doyum verici mutluluğun onlara değerli olduğunu hissettirmek olduğundan ve insan başka insanların desteğine güvendiğinde hastalık ya da kötü bir olayın onu kötü hale getirme ihtimalinin daha düşük olduğundan bahsetmiştir (Csikszentmihalyi, 2005). Arkadaş çevresinin fazla olmasıyla birlikte yalnızlığ hissetmeme kişinin mutlu olmasinda önemli bir faktördür (Cheng ve Furnham, 2002). Benzer biçimde araştırmacılar evli, sosyal iletişimleri güçlü, arkadaş çevresi fazla kişilerin yani yalnız olmayan kişilerin daha mutlu olduğunu açıklamışlardır (Lyubomirsky, Sheldon ve Schkade, 2005).

Mutluluk ile sabır ölçeği puanları arasında anlamlı orta düzeyde pozitif ilişki bulunmuştur. Yani üniversite öğrencilerinde mutluluk arttıkça sabır düzeyinin de arttı̆̆ görülmüştür. Bu bulguyu destekler nitelikte çalışmalar mevcuttur.Sabır düzeyinin mutluluğu artırdığı saptanmıştır (Deng, Li, Wang, ve Zhang, 2019).

Yalnızlık ile sabır ölçeği puanları arasında anlamlı düşük düzeyde negatif ilişki bulunmuştur. Üniversite öğrencilerinde sabır arttıkça yalnızlığın azaldığı görülmüştür.

\section{Sonuç ve Öneriler}

Bu araştırmadan elde edilen sonuçlar kapsamında araştırmacılara, eğitimcilere ve ebeveynlere şu önerilerde bulunulabilir: Mutluluk kavramının yaşam doyumu, öznel iyi oluş, kendini toparlama gücü gibi kavramlarla ilişkisi incelenebilir. Mutluluk düzeyleri yüksek olan üniversite öğrencilerinin daha az yalnızlık duygusunu yaşadıkları ve sabır eğilimleri yüksek olan öğrencilerin de daha mutlu oldukları sonucundan yola çıkarak eğitim programları, seminerler, bireysel ve grupla psikolojik danışma çalışmaları düzenlenebilir. Mutluluğun bireyin gelişim süreçleri içinde nasıl değiştiğini görebilmek için boylamsal çalışmalar yapılabilir. Bu araştırma yalnızca üniversite öğrencileri üzerinde yapılmıştır farklı yaş gruplarıyla benzer çalışmalar yapılabilir. 


\title{
EXTENDED ABSTRACT
}

\section{An Examination of the Relationship between Happiness, Loneliness and Patience Levels of University Students}

\author{
Zeliha Traş - Kemal Öztemel - Merve Koçak \\ Necmettin Erbakan University, Gazi University
}

Positive psychology is considered as contentment, satisfaction, and wellbeing about the past; and as optimism and hope for the future (Seligman and Csikszentmihalyi, 2000). Happiness can be expressed as how positive a person can evaluate her/his life (Bülbül and Giray, 2011). It also allows an individual to be mentally positive and feel better (Fromm, 1994). Happiness is explained as experiencing negative emotions less than positive ones. (Diener, 1984; Myers and Diener 1995). One of the variables, whose relationship with happiness is examined, is loneliness. It is expected that when a person feels happy s/he would feel less lonely because of the great circle of friends (Cheng and Furnham, 2002). The situation, that arises when an individual feels rejected, unrecognized, and misunderstood in social relationships and cannot establish emotional relationship with people, is called loneliness (Ünlü, 2015). One of the concepts that determine happiness is patience. As for patience, it is an individual's capacity to wait calmly in the face of disappointment, pain, stress, and trouble (Schnitker, 2012). Patience gives strength to an individual in the face of difficulties that $\mathrm{s} / \mathrm{he}$ faces until the end of her/his life and then mediates her/his happiness (Doğan and Gülmez, 2014). The aim of this study is to examine the relationship between university students' happiness, loneliness and patience levels.

\section{Method}

\section{Research Model}

This research was carried out according to the relational screening model. The screening model is the one that aims to detect the past or ongoing situation as it is (Karasar, 2018). 


\section{Study group}

The participants of the study consist of 301 students studying at a public university in Central Anatolia. Simple random (unbiased sampling) sampling method was used (Karasar, 2018). 227 (75.7\%) of the participants are women and $73(24.3 \%)$ are men. The ages of the participants range between 17 and $37(\mathrm{sd}=2.20)$.

\section{Processing}

\section{Data Collection Tools}

The Oxford Happiness Questionnaire: OHQ, developed by Hills and Argyle, consists of 29 items that can be answered on 6-point Likert scale (Doğan \& Sapmaz, 2012). High scores in OHQ mean that the level of happiness is high. The Cronbach's Alpha value for this research is 0.88 .

The Patience Scale: The scale, developed by Schnitker and Emmons (2007), was adapted by Eliüşük and Arslan (2016). It is a self-assessment scale that determines the beliefs of individuals about the concept of patience. The Cronbach's Alpha value for this research is 0.83 .

The Social and Emotional Loneliness Scale: The scale was developed by DiTommaso, Brannen and Best (2004) and adapted to Turkish by Çeçen (2007). It consists of three dimensions of relationships as domestic, romantic and social. The Cronbach's Alpha value for this research is 0.74 .

\section{Data Analysis}

At the end of the research, the data were analyzed using SPSS 20.0 package program. For the analysis of the data, multiple linear regression was used, which is an analysis for predicting the dependent variable based on two or more independent variables (patience and loneliness) associated with the dependent variable (happiness) (Büyüköztürk, 2018). The correlation between the scores obtained from the scales was calculated using the Pearson Correlation coefficient.

\section{Results}

According to Pearson Correlation Coefficient analysis, significant relationships were found between happiness, which is the dependent variable, 
and the independent variables (loneliness, patience). Students with high happiness scores have high patience scores $(\mathrm{r}=.535, \mathrm{p}<.01)$, and their loneliness scores are low $(r=-.292, \mathrm{p}<.01)$. Patients with high loneliness scores have low patience scores $(\mathrm{r}=-.131, \mathrm{p}<.01)$.

According to the results of the regression analysis, the happiness scores of university students together with the variables of patience and loneliness give a high level and significant relationship $(R=.580, R 2=.336, p$ $<.001)$. Together with the predictive variables, it predicts $33 \%$ of the total variance in happiness. According to the standardized regression coefficient $(\beta)$, the relative importance order of independent variables on happiness is patience $(\beta=.506, \mathrm{t}=10.620, \mathrm{p}<.001)$ and loneliness $(\beta=-.226, \mathrm{t}=-$ $4.740, \mathrm{p}<.001)$.

\section{Discussion and conclusion}

There are significant relationships between happiness, the dependent variable, and the independent variables (loneliness and patience). Students with high happiness scores have high patience scores, and low loneliness scores. Patients with high loneliness scores have low patience scores.

A significant and low negative relationship was found between happiness and loneliness scale scores. In other words, in university students, as happiness increases, loneliness decreases. There are studies supporting this finding. The most satisfying happiness for people is to make others feel dignified (Csikszentmihalyi, 2005). Not feeling the loneliness with a great circle of friends is an important factor in making a person happy (Cheng and Furnham, 2002). Similarly, the researchers explained that people who are married, have strong social communication, and have a great circle of friends, namely those who are not alone, are happier (Lyubomirsky, Sheldon and Schkade, 2005). It was seen that the level of patience increases as happiness increases among university students. There are studies supporting this finding. Patience has been found to increase happiness (Deng, Li, Wang, and Zhang, 2019).

\section{Conclusion and Suggestions}

Educational programs, individual and group counseling activities can be organized to increase the happiness levels of students. 
Group guidance program can be implemented in a way to cover the relationship of university students with the social groups around them.

\section{Kaynakça / References}

Aahababaei, N. ve Tabik, T. (2015). Patience and mental health in Iranian students. Iran J Psychiatry Behav Sci, 9(3), 1-4. doi: 10.17795/ ijpbs-1252

Arslan, C. ve Eliüşük, A.(2016). Sabır ölçeğinin Türkçe 'ye uyarlanması: Geçerlilik ve güvenirlik çalışmaları. Değerler Ĕ̆itimi Dergisi, 14, 67-86.

Aydemir, E. R. (2008). Dindarlık ve mutluluk ilişkisi. Yayınlanmamış yüksek lisans tezi, Sosyal Bilimler Enstitüsü, Samsun.

Bowlby, J.(2014).Güvenli bir dayanak: Ebeveyn-çocuk bağlanması ve sağlkkl insan gelişimi.(S.Güneri, Çev.).İstanbul:Psikoterapi Enstitüsü Eğitim Yayınları.

Bülbül, S. ve Giray, S. (2011). Sosyodemografik özellikler ile mutluluk algisı arasındaki ilişki yapısın analizi. Ege Akademik Bakis, 11, 113.

Büyüköztürk, Ş.(2018). Sosyal bilimler için veri analizi el kitabı. Ankara: Pegem Akademi.

Cheng, H. ve Furnham, A. (2002). Personality, Peer Relations, and SelfConfidence as Predictors of Happiness and Loneliness. Journal of Adolescence, 25(3), 327-339.

Csikszentmihaly, M. (2005). Akış: Mutluluk bilimi. (Çev. S.K.Akbaş). Ankara: HYB Yayıncılık. (Orijinal çalışmanın yayın tarihi 1990)

Çeçen, A.R. (2007). Üniversite öğrencilerinin cinsiyet ve yaşam doyumu düzeylerine göre sosyal ve duygusal yalnızlık düzeylerinin incelenmesi. Mersin Üniversitesi Ĕ̆itim Fakültesi Dergisi, 3 (2), 180-190.

De Jong, G. J. (1998). A review of loneliness: Concept and definitions, determinants and consequences. Reviews In Clinical Gerontology, 8, 73- 80.

Deng, J., Li, T., Wang, J.,ve Zhang, R. (2019). Optimistically Accepting Suffering Boosts Happiness: Associations Between Buddhism Patience, Selflessness, and Subjective Authentic-Durable Happiness. Journal of Happiness Studies, Advanced online publication, doi:10.1007/s10902019-00083-0

Diener, E. (1984). Subjective well-being. Psychological Bulletin, 95, 542-75.

Diener, E. , Suh, E. ve Oishi, S. (1997).Recent findings on subjective wellbeing. Indian Journal of Clinical Psychology, 24(1), 25- 41. 
DiTommaso, E., Brannen, C., ve Best, L. A. (2004). Measurement and validity characteristics of the short version of the social and emotional loneliness scale for adults. Educational and Psychological Measurement, 64(1), 99-119. doi:10.1177/0013164403258450

Doğan, M. ve Gülmez, Ç. (2014). Sabır ölçeğinin Türkçe'ye uyarlanması: Geçerlik ve güvenirlik çalışması. Atatürk Üniversitesi İlahiyat Fakültesi Dergisi, 42, 264-269.

Doğan, T. ve Sapmaz, F. (2012). Oxford mutluluk ölçeği Türkçe formunun psikometrik özelliklerinin üniversite öğrencilerinde incelenmesi. Düşünen Adam Psikiyatri ve Nörolojik Bilimler Dergisi, 25, 297-304.

Döş, İ. (2013). Mutlu okul. Eğitim ve Bilim, 38 (170), 266-280.

Eliüşük, A., ve Arslan, C. (2016). Sabır ölçeğinin Türkçe'ye uyarlanması: Geçerlilik ve güvenirlik çalışmaları. Değerler Eğitimi Dergisi, 14(31), 67-86.

Fromm, E. (1994). Sevginin ve şiddetin kaynağı. (Y. Salman ve N. İçten, Çev.) İstanbul: Payel Yayınevi.

Geçtan, E. (2012).Psikanaliz ve sonrası. (15. Bsm).İstanbul: Metis Yayınları.

Hills, P. ve Argyle, M. (2002). The Oxford Happiness Questionnaire: A compact scale for the measuremen of psychological well-being. Personality and Individual Differences, 33, 1073-1082.

İlhan, T. (2009). Üniversite öğrencilerinin benlik uyumu modeli: Yaşam amaçları, temel psikolojik ihtiyaçlar ve öznel iyi oluş. Gazi Üniversitesi Eğitim Bilimleri Enstitüsü, Ankara.

Karasar, N.(2018). Bilimsel alg̨ çerçevesi ile bilimsel araştırma yöntemi. Ankara: Nobel Yayıncilik.

Larson, R. (1990). The solitary side of life : An examination of the time people spend alone from childhood to old age. Developmental Review, 10, 155183.

Lyubomirsky, S. (2008). Nasıl mutlu olunur. (G.Göze, Çev.),İstanbul: Mediacat Kitapları.

Lyubomirsky, S., Sheldon, K. M. ve Schkade, D. (2005). Pursuing happiness: The architecture of sustainable change. Review of General Psychology, 9(2), 111- 131.

Maclntyre, A.(2001). Ethik'in kısa tarihi. (H.Hünler, Çev.) İstanbul: Paradigma Yayınevi.

Myers, D.G., Diener, E. (1995). Who is happy? Psychological Science, 6 (1), 1017. https://doi.org/10.1111\%2Fj.1467-9280.1995.tb00298.x

Özdoğan, Ö.(2006).Mutluluğu seçiyorum. İstanbul: Lotus Yayınevi. 
Rogers, C. (1994). Etkileşim Grupları. (H. Erbil,Çev.). Ankara: Ekin Yayınları. Rook, K. (1984). Promoting social bonding: Strategies for helping the lonely and socially isolated. American Psychlogist, 39(12), 1389-1407.

Sayın, E. (2012). Tasavvuf kültüründeki sabır kavramının psikolojik etkileri. Batman Üniversitesi Yaşam Bilimleri Dergisi. 1(1), 414-419.

Seligman, M. E. P. ve Csikszentmihalyi, M. (2000). Positive psychology: an introduction. American Psychologist, 55, 5-14.

Schnitker S. A. (2012). An examination of patience and well-being. The Journal of Positive Psychology, 7(4), 263-280.

Ünlü, F.(2015).Ebeveyni boşanmış bireylerde benlik saygısı, yalnızlık ve bă̆lanma stilleri arasındaki ilişkinin incelenmesi. Yüksek Lisans Tezi, Sosyal Bilimler Enstitüsü, İstanbul.

Yalom, I.(2013). Varoluş̧̧u psikoterapi.(Çev. Z. Babayiğit). İstanbul:Kabalcı Yayınevi,.

Weiss, R. S. (1973). Loneliness: The experience of emotional and social isolation. Cambridge, MA: MIT Press.

\section{Kaynakça Bilgisi / Citation Information}

Traş, Z., Öztemel, K. ve Koçak, M. (2020). Üniversite öğrencilerinin mutluluk, yalnızlık ve sabır düzeyleri arasındaki ilişkinin incelenmesi OPUS-Uluslararası Toplum Araştırmaları Dergisi , 15(22), 878-894. DOI: $10.26466-/ o p u s .575329$ 